\title{
O jogo como atividade: contribuições da teoria histórico-cultural
}

\author{
Carolina Picchetti Nascimento \\ Elaine Sampaio Araujo \\ Marlene da Rocha Miguéis
}

\begin{abstract}
Resumo
Neste artigo, analisamos o jogo protagonizado (jogo de papéis), buscando compreender o seu papel no desenvolvimento da criança e a sua relação com a organização do ensino na infância. Tendo a teoria histórico-cultural como a que fundamenta este trabalho, assumimos uma concepção de desenvolvimento eminentemente histórica, na qual o desenvolvimento do psiquismo é determinado por relações socioculturais mediadas. Nesta perspectiva, o jogo é entendido como uma atividade na qual o homem reconstrói as relações sociais e, nesse processo, formam-se novas funções psíquicas. Desse modo, o jogo protagonizado surge como uma forma peculiar e específica da atividade humana pela qual as crianças se apropriam da experiência social da humanidade e se desenvolvem como personalidade. Na organização do ensino, o educador não deve apenas utilizar o jogo como instrumento, mas ter por objetivo revelar as relações humanas presentes nele, para que as crianças possam delas se apropriar.
\end{abstract}

Palavras-chave: Ensino, aprendizagem, psicologia histórico-cultural.

\section{Game as an activity: contributions from the historical-cultural theory}

\begin{abstract}
In this article, we analyze the role-playing, its influence on the children development and its relationship with the organization of teaching in the childhood. Based on Historico-Cultural theory, we assume a historical conception in which the development of the psychic is determined by mediated social-cultural relationships. From this view, the role-playing is understood as an activity in which we rebuild social relations and in this process we form new psychic functions. In this way, the role-playing game emerges as a peculiar and specific human activity, in which children appropriate human social experience and develop themselves as a personality. During the teaching organization, the early childhood teacher should not only use role-playing as a tool, but also as a goal in order to reveal human relationships present in playing so that children can appropriate them.
\end{abstract}

Keywords: Teaching, learning, historical-cultural psychology.

\section{El juego como actividad: contribuciones de la teoría histórico-cultural}

\begin{abstract}
Resumen
En este artículo analizamos el juego protagonizado (juego de papeles/roles), buscando comprender su papel en el desenvolvimiento del niño y su relación con la organización de enseñanza en la infancia. Tomando a la teoría histórico-cultural como la que fundamenta este trabajo, asumimos una concepción de desenvolvimiento eminentemente histórica, en la cual el desenvolvimiento del psiquismo es determinado por relaciones socio-culturales mediadas. En esta perspectiva el juego es entendido como una actividad en la cual el hombre reconstruye las relaciones sociales $y$, en ese proceso, se forman nuevas funciones psíquicas. De ese modo, el juego protagonizado surge como una forma peculiar y específica de actividad humana por la cual los niños se apropian de la experiencia social de la humanidad y se desenvuelven como personalidad. En la organización de la enseñanza, el educador no debe sólo utilizar el juego como instrumento, sino más bien tener por objetivo revelar las relaciones humanas presentes en éste, para que los niños puedan apropiarse de ellas.
\end{abstract}

Palabras-clave: Ensenanza, aprendizaje, psicologia historico-cultural. 


\section{Introdução}

Neste artigo, analisamos o jogo protagonizado (jogo de papéis) buscando compreender o seu papel no desenvolvimento da criança e a sua relação com a organização do ensino na infância. Trata-se de um estudo teórico acerca dos conceitos de jogo, desenvolvimento e aprendizagem na infância. A fonte principal para a realização do estudo foi a produção bibliográfica de autores pertencentes à psicologia histórico-cultural, o que demandou o estudo das bases teórico-metodológicas desses autores, no caso, o materialismo histórico e o materialismo dialético. Nesse sentido, o movimento de pesquisa requereu compreender os princípios filosóficos e epistemológicos que orientam a teoria histórico-cultural, dos quais depreendemos, particularmente, a compreensão do trabalho como atividade constitutiva da condição humana. Nessa mesma direção, os estudos relacionados à Teoria da Atividade oferecem a possibilidade de compreendermos o jogo não como uma atividade própria à criança, mas como atividade constitutiva da condição infantil.

Ao defendermos o jogo como atividade e, também, o caráter histórico de sua gênese, interessa-nos realizar uma discussão sobre o papel da imaginação no jogo protagonizado e sobre a compreensão desse jogo na qualidade de zona de desenvolvimento próximo. A partir dessas discussões, destacamos a intencionalidade pedagógica no trabalho educativo com o jogo, indicando alguns fatores que podem contribuir para uma prática pedagógica na educação infantil na qual o jogo seja efetivamente a atividade principal da criança.

\section{O jogo na teoria histórico-cultural}

As principais correntes teóricas sobre 0 desenvolvimento humano, dentre as quais podemos citar as piagetianas, as wallonianas e as winnicottianas, abordam (com maior ou menor destaque) o jogo como objeto de seus estudos. Em termos educacionais, muitas dessas teorias fundamentaram estudos sobre o uso pedagógico do jogo na escola, resultando em um número considerável de publicações sobre o tema. Na década de noventa, por exemplo, foi amplamente divulgada, no Brasil, a obra Jogo e Educação de Gilles Brougère (1998), na qual o autor traça um panorama do jogo em diferentes abordagens procurando estabelecer o seu papel para a educação infantil. Podemos perceber certa orientação do autor para os contributos da psicologia que valorizam os aspectos sociais do jogo, demarcando-se uma posição em que o jogo é visto como uma atividade natural da criança.

Emcomum, poderíamos dizerque todos esses estudos (os de referência e os decorrentes) consideram, de um modo ou de outro, a relação entre o desenvolvimento humano e o jogo. Isto significa tanto o entendimento da existência de um período especial da vida humana (a infância), quanto o de que, nesse período, o jogo desempenha um papel fundamental no processo de desenvolvimento do sujeito.

Nesse sentido, parece coerente afirmarmos que o entendimento do jogo é a base para a compreensão do desenvolvimento da criança. Nessa lógica, uma teoria do jogo nos conduziria a uma determinada concepção de desenvolvimento e de infância, o que justificaria, em grande parte, os esforços de pesquisa nesta área. Entretanto, se afirmássemos isso, partiríamos de uma premissa equivocada. Qualquer teoria que se disponha a estudar o jogo, não o faz para conseguir elaborar uma concepção de desenvolvimento e de infância. O processo é justamente o oposto: tem-se uma concepção de desenvolvimento e de infância (quer ela seja oculta ou explícita) e é ela que definirá, em última instância, o direcionamento das teorias sobre o jogo.

A teoria histórico-cultural ${ }^{1}$, na qual fundamentamos este trabalho, define uma concepção de desenvolvimento eminentemente histórica, superando tanto os determinismos biológicos quanto os sociológicos. O processo de desenvolvimento humano "se efetua sob a influência determinante das condições de vida e de educação, em correspondência com o meio ambiente e sob a influência diretriz dos adultos." (Elkonin, 1969, p. 193).

Dessa forma, a tese central desta teoria é a de que o desenvolvimento do psiquismo é determinado pelas relações socioculturais mediadas, isto é: a atividade prática é determinante do desenvolvimento da mente. Essa compreensão sobre o desenvolvimento do psiquismo ancorase na célebre tese de Marx e Engels (1977, p.37): "Não é a consciência que determina a vida, mas a vida que determina a consciência". E foi justamente essa concepção de homem que possibilitou criar uma teoria histórica do jogo ${ }^{2}$.

Os escritos de Vigotski ${ }^{3}$ (2000) e Leontiev (1988) sobre as relações entre o jogo e o desenvolvimento estabeleceram o jogo como uma atividade especial da criança, não só porque permite que ocorram importantes transformações psíquicas no sujeito (plano ontogenético), mas também porque se trata de uma atividade que só pode surgir em um determinado momento da vida em sociedade (plano filogenético). Em termos gerais, o jogo é compreendido como uma "atividade em que se reconstroem, sem fins utilitários diretos, as relações sociais" (Elkonin, 1998, p.19). Nesse sentido, podemos compreender a razão pela qual se afirma que a base do jogo é social "devido precisamente a que também o são sua natureza e sua origem, ou seja, a que o jogo nasce das condições da vida da criança em sociedade" (Elkonin, 1998, p.36).

Elkonin (1998), a partir das contribuições teóricometodológicas da psicologia histórico-cultural sobre o jogo,

\footnotetext{
1 Esta teoria tem como princípio orientador a dimensão históricocultural do psiquismo humano. A dimensão histórica responde a três aspectos: desenvolvimento da história natural, desenvolvimento da humanidade e desenvolvimento da história individual. A dimensão cultural relaciona-se com a compreensão de que o homem se organiza, formando grupos humanos em torno de uma determinada atividade laboral, utilizando-se sobretudo da linguagem. Nesse sentido, a cultura é a objetivação do trabalho que os homens realizam coletivamente.

2 Consideramos aqui todas as modalidades de atividades lúdicas das crianças.

3 Neste texto optamos pela grafia Vigotski, porém, em respeito às referências, o nome do autor aparecerá, também, grafado conforme a fonte.
} 
sobretudo as esboçadas por Vigotski e Leontiev, tomou como objeto de estudo uma modalidade particular dessa atividade, o jogo protagonizado (jogo de papéis). O autor tinha como interesse investigar "a natureza e o conteúdo do jogo de papéis, a psicologia dessa forma evoluída da atividade lúdica, sua origem, seu desenvolvimento e decadência, sua importância para a vida e o desenvolvimento da criança como futura personalidade" (Elkonin, 1998, p. 21).

Em síntese, para entendermos o jogo e o lugar que ele ocupa na psicologia histórico-cultural, precisamos entendêlo, primeiramente, como uma forma peculiar e específica da atividade humana pela qual as crianças se apropriam da experiência social da humanidade e se desenvolvem como personalidade ${ }^{4}$. O trabalho é a forma específica e superior de manifestação da atividade humana (Shuare, 1990) e o jogo é a forma específica de manifestação da atividade humana na criança.

Esta concepção do jogo implica, como afirma Ruiz (1992), uma investigação histórica para compreender o atual papel do jogo no desenvolvimento da criança e para a compreensão de que nem sua forma e nem sua função são independentes dos sistemas sociais produzidos historicamente.

\section{A Teoria da Atividade como base da concepção histórica do desenvolvimento humano}

Assumir a teoria histórico-cultural como fundamento para pensarmos os processos de desenvolvimento humano e de formação de sua personalidade, particularmente na infância, significa compreender a socialização como fonte primária e fundamental do desenvolvimento. Socialização essa presente desde o primeiro dia de vida. O homem é um ser social desde que nasce, posto que sua vida está, desde o início, mediada pela relação que estabelece com os outros homens, ou seja, pelas relações sociais.

As relações interpessoais fazem parte das relações sociais e são relações históricas, antes de privadas. Este entendimento parte da definição de que o homem é a síntese ou o conjunto das relações sociais, síntese de múltiplas relações (Marx \& Engels, 1977; Saviani, 2003). Assim, embora a relação criança/mundo possa se dar, na aparência, mediada por apenas um indivíduo (por exemplo, a mãe), esse indivíduo carrega em si o conjunto de relações sociais de seu tempo. Nas palavras de Vigotski, "a relação da criança com a realidade circundante é social desde o início. Desde esse ponto de vista, podemos definir a criança como um ser maximamente social" (Vygotski, 1996, p.285).

Entretanto, afirmar simplesmente essa condição eminentemente social do ser humano pode, sem dúvida, levar-nos a uma postura determinista do papel da cultura e da sociedade nos processos de desenvolvimento do sujeito. O que nos permite realizar a análise sobre o papel da socialização na formação dos sujeitos, numa base

4 Entendemos personalidade "como uma realidade psíquica, pessoal e construída. Esta natureza da personalidade tem na pessoa suas respectivas premissas nas interações entre o natural, o individual, $o$ social, o herdado e o aprendido" (Castañeda, 2003, p.4) . verdadeiramente histórica, são as condições concretas de vida da criança: a forma como ela está e a forma como ela age no mundo, em outras palavras, a sua forma de Atividade (Leontiev, 1983, 1987).

De fato, são as circunstâncias objetivas (o modo de vida historicamente existente em dada sociedade) que produzem a personalidade dos indivíduos, que os constituem como sujeito. Mas essas circunstâncias não atuam nunca de modo direto sobre os indivíduos: elas são sempre mediadas por um conjunto de atividades que, por sua vez, servem como mediador da relação homem/mundo. Como explica Leontiev (1983, p. 63), "com toda a sua peculiaridade, a atividade do indivíduo humano constitui um sistema compreendido no sistema de relações na sociedade. Fora destas relações, a atividade humana não existe em geral".

Assim como qualquer ser vivo, o homem, na sua relação com o mundo, apresenta necessidades que devem ser satisfeitas. Entretanto, qualquer necessidade que se apresente ao homem será sempre satisfeita por intermédio de uma atividade, que converge para si as ações e operações que o sujeito realiza ${ }^{5}$. Nesta medida, as necessidades, que são satisfeitas mediante uma atividade humana, humanizamse. Como diz ainda Leontiev (1987), não é qualquer processo que pode ser chamado de atividade:

Por esse termo designamos apenas aqueles processos que, realizando as relações do homem com o mundo, satisfazem uma necessidade especial correspondente a ele.(...) Por atividade, designamos os processos psicologicamente caracterizados por aquilo a que o processo como um todo se dirige (seu objeto), coincidindo sempre com o objetivo que estimula o sujeito a executar esta atividade, isto é, o motivo (p.68).

Retomando a compreensão de que o jogo é uma atividade, na conceituação elaborada por Leontiev (1983, 1987), com necessidades, motivos, ações e operações e, portanto, uma forma específica do homem se relacionar com o mundo, é que passaremos a analisar o jogo e seu papel no desenvolvimento da criança.

\subsection{Jogo como atividade: processo histórico de sua gênese}

Não existe uma "natureza infantil" para o jogo. A própria concepção de "natureza infantil" atrelada a uma visão metafísica de mundo é falsa. Segundo Charlot (1979, p. 252), esse equívoco teórico se dá pelo entendimento de que a "natureza infantil remete a características que têm um valor absoluto e universal: a criança, em si, é selvagem, submissa a sua sensibilidade, inocente, espontânea, indisciplinada etc.", como se fosse possível considerar a condição infantil de modo abstrato. Neste sentido, ao analisarmos as questões sobre a necessidade do jogo e o seu motivo, não a encontraremos na criança em si mesma, em sua suposta natureza abstrata, mas sim nas condições que permitiram o surgimento do jogo na humanidade e nas

5 A atividade coincide sempre com o objeto que estimula o sujeito a executar essa atividade, criando, então, o motivo da atividade. 
condições que fazem dele uma atividade para as crianças na contemporaneidade.

Em uma concepção materialista-histórico-dialética do homem (fundamento da teoria-histórico-cultural), o trabalho é a base de todas as atividades humanas. É a primeira atividade (filogeneticamente) que ocupa o lugar de atividade principal e que regula os modos de ações do homem com o mundo, com os outros e consigo mesmo. Neste sentido, o jogo de papéis nem sempre foi uma realidade e um elemento fundamental para as crianças de outras épocas da história, pelo contrário, ele surgiu em momentos posteriores do processo de filogênese do homem. Elkonin (1998) faz uma interessante análise do processo de surgimento do jogo na humanidade. Nas sociedades pautadas num "regime de comunismo primitivo", o acesso ao mundo adulto, mundo cujas relações de trabalho eram ainda pouco desenvolvidas, dava-se de maneira direta para todos os membros da comunidade. Tão logo Ihes era permitido, corporalmente, participar das atividades dos adultos, as crianças tomavam parte dessas atividades. Assim, o mundo adulto (a atividade do adulto, atividade essa de trabalho) era, desde cedo, acessível à criança, de modo que o jogo, como forma peculiar de a criança reconstituir esse mundo e dele se apropriar, era desnecessário.

Supomos que, nesse momento histórico da humanidade, uma criança comece a utilizar um machado para cortar troncos de árvores, tal qual vê seu pai fazendo. O machado é menor do que aquele utilizado pelos adultos e, possivelmente, mais leve, adequado às características físicas da criança. Poderíamos dizer, nessas condições hipoteticamente narradas por nós, que a criança estava em atividade de jogo? Se concebermos a existência de uma "natureza infantil", responderíamos que sim: porque se trata de uma criança e o jogo faz parte de sua natureza. Assim, qualquer tarefa que uma criança realize será transformada, por ela mesma, em uma tarefa "lúdica". Sua fantasia transformaria a realidade e ela passaria a viver nesse pequeno mundo criado por ela mesma. Contudo, se rechaçamos essa concepção de natureza infantil, devemos buscar a resposta de outro modo: nas condições da atividade da criança e no sentido dessa atividade para ela.

No exemplo dado, ainda que o machado fosse menor, adaptado às condições físicas da criança, ela tinha nas mãos um instrumento real (funcional), que lhe permitia reproduzir as ações e os resultados das atividades dos adultos. E, ainda mais importante, a criança tinha como necessidade a produção de lenha para a sua comunidade e não a simples imitação de seu pai. Imitar os gestos dos adultos tinha como orientação a possibilidade de criar os mesmos resultados materiais que os adultos obtinham. Neste sentido, a criança estava inserida numa atividade de trabalho.

O processo de gênese do jogo na história da humanidade, então, não pôde aparecer nem antes do trabalho, nem antes da arte (Elkonin, 1998). Este mesmo autor sintetiza sua compreensão a respeito do processo de surgimento e desenvolvimento do jogo:
Assim, pode-se formular a tese mais importante para a teoria do Jogo protagonizado: esse jogo nasce no decorrer do desenvolvimento histórico da sociedade como resultado da mudança de lugar da criança no sistema de relações sociais. Por conseguinte, é de origem e natureza sociais. (Elkonin, 1998, p. 80)

Deste modo, em um determinado momento da humanidade, com a complexificação das atividades de trabalho (tanto no que diz respeito às relações de produção quanto aos próprios instrumentos), o mundo adulto, sob muitos aspectos, não mais estava diretamente acessível à criança; ela não podia participar direta e efetivamente de muitas atividades compartilhadas pelos adultos. Entretanto, a apropriação de tal mundo (mundo humano) é uma necessidade para a criança, posto que ela faz parte dele e precisa, cada vez mais e melhor, situar-se nesse mundo. É nesse sentido que Leontiev (1988, p.120), ao distinguir a atividade lúdica entre os animais e as crianças, afirma que "a brincadeira na criança não é instintiva, mas precisamente humana, atividade objetiva, que, por constituir a base da percepção que a criança tem do mundo dos objetos humanos, determina o conteúdo de suas brincadeiras".

Foi neste momento e mediante essas condições que o jogo pôde assumir um caráter tão específico e importante no processo de desenvolvimento humano, constituindose, hoje (na maioria das sociedades), a atividade principal da criança na educação infantil, isto é, aquela atividade que melhor realiza a relação criança/mundo, no sentido de permitir a máxima apropriação das produções culturais historicamente elaboradas.

\subsection{A imaginação no jogo: premissa ou produto?}

Ao defender que é por meio da apropriação que se dá o desenvolvimento cultural do homem (premissa da teoria histórico-cultural), o jogo adquire um papel fundamental na teoria do desenvolvimento infantil. Ojogo de papéis reconstitui a realidade de uma maneira singular (Elkonin,1998). As regras e as normas existentes entre as pessoas, nas situações da vida (relações de trabalho, por exemplo) são reconstituídas por meios singulares e aparecem de maneira mais ampla e mais explícita na consciência das pessoas, por meio das situações simbólicas. Isso tem a ver com a função do jogo de papéis ou a sua necessidade: permitir que as crianças se apropriem do mundo de relações e atividades dos adultos e, assim, humanizem-se.

Parece importante, neste momento, discutirmos o que vem a ser essa reconstituição singular da realidade no jogo, de que forma a realidade pode ser reproduzida pela criança no jogo e qual o papel da imaginação ou fantasia nesse processo. Em relação à imaginação, a primeira consideração é a de que a criança não imagina para jogar, mas no processo de jogo ela imagina. Essa compreensão rompe com a lógica segundo a qual a imaginação é premissa para o desenvolvimento do jogo. Como se sustenta esta afirmação? A partir da compreensão de que a consciência é formada 
historicamente, ou seja, a imaginação como uma das funções psicológicas superiores é constituída historicamente. Não se trata de primeiro imaginar para depois jogar, pelo contrário, ao jogar, a criança desenvolve sua imaginação. Leontiev ilustra esse movimento ao discutir sobre como isso se dá, por exemplo, na atividade lúdica de montar um cavalinho de pau, na qual frequentemente se supõe que a criança galopa com o pedaço de pau porque sua imaginação "foi ativada", ou seja, porque ela imagina que se trata de um cavalo. $O$ autor rebate essa questão argumentando que:

\begin{abstract}
Esta explicação não é apenas realmente falsa, mas é, em princípio, infundada. Este é apenas um tipo de explicação, um tipo de estudo da atividade infantil que a deduz a partir de mudanças já existentes em sua consciência e formadas alhures, enquanto a linha principal da análise psicológica deveria tomar sempre a direção oposta. Isto é, deveria começar por examinar a real atividade da criança para, com isto, compreender as mudanças correspondentes em sua consciência, e só então descobrir o efeito contrário desta consciência, agora modificada, no desenvolvimento posterior da atividade (Leontiev, 1988, p. 125).
\end{abstract}

Nesse sentido, é importante compreender que, ao jogar, a criança reproduzirá de modo singular um determinado aspecto da realidade. Para realizar as ações e operações do mundo adulto em seu jogo, a criança precisa, antes, realizar determinadas substituições: ela substitui o objeto utilizado na atividade dos adultos por um objeto que Ihe seja realmente acessível. Por essa razão, a utilização do pedaço de pau como cavalo, antes de ser resultado da imaginação infantil, está relacionado com as condições objetivas; o pedaço de madeira é um objeto acessível à criança e torna-se, então, um modo pelo qual a ação (no caso montar um cavalo) pode ser realizada por ela.

A substituição de objetos é, assim, uma necessidade para que a reprodução das ações dos adultos, no jogo, possa se dar. Mas, se no plano dos objetos as substituições são aceitáveis e mesmo necessárias, no plano das ações com os objetos (o conteúdo e a sequência das ações), não pode haver substituições: elas devem corresponder à situação real. Leontiev (1988) analisa uma situação de jogo na qual essa relação fica evidente. Ao brincar de médico, de aplicar injeções nos pacientes, os objetos que são realmente utilizados pelos adultos podem ser facilmente substituídos: um pauzinho ${ }^{6}$ torna-se a injeção; um pedaço de papel, o algodão; um líquido fictício, o álcool. Contudo, modificar a estrutura da atividade do adulto, o seu conteúdo e a sequência das ações não é admitido pela criança, já que a afasta da realidade humana da qual ela deseja apropriarse. Assim, no exemplo dado, a criança não admitirá aplicar a injeção e depois passar o álcool, nem tampouco aplicar a injeção e depois fazer o diagnóstico do paciente.

6 Não é qualquer objeto que pode substituir o objeto original. O objeto substituto deve garantir que a criança consiga reproduzir a ação original com ele. No exemplo dado, uma bola dificilmente seria aceita como substituto da injeção, embora no plano puramente simbólico pudéssemos tomar uma bola por uma injeção. Mas, como diz Vigotski (2000), a atividade da criança é o jogo e não a simbolização.
Deste modo, longe de ser uma forma de a criança afastar-se do mundo real (como, muitas vezes, defendem as teorias naturalizantes do jogo), o jogo é justamente a forma pela qual a criança pode apropriar-se cada vez mais desse mundo, aproximar-se cada vez mais dele.

É nesse processo de reconstituição da realidade, o qual obriga a criança a realizar substituições dos objetos para reproduzir determinada atividade do adulto, que surge a necessidade da imaginação. A imaginação, reafirmamos, não é premissa para o jogo, mas, justamente, seu produto.

Portanto, nas premissas psicológicas do jogo não há elementos fantásticos. Há uma ação real, uma operação real e imagens reais de objetos reais, mas a criança, apesar de tudo, age com a vara como se fosse um cavalo, e isto indica que há algo imaginário no jogo como um todo, que é a situação imaginária. Em outras palavras, a estrutura da atividade lúdica é tal que ocasiona o surgimento de uma situação lúdica imaginária.

\section{$(\ldots)$}

É preciso acentuar que a ação, no brinquedo, não provém da situação imaginária mas, pelo contrário, é esta que nasce da discrepância entre a operação e ação; assim, não é a imaginação que determina a ação, mas são as condições da ação que tornam necessária a imaginação e dão origem a ela (Leontiev, 1988, p. 127).

A questão das substituições dos objetos no jogo não pode ser analisada apenas como uma questão de "ausência" dos materiais concretos utilizados pelos adultos. Tampouco deve ser encarada como uma questão de simples "falta de capacidade" da criança para operar com esses objetos. Muitas crianças operam habilidosamente com facas, cortando cana de açúcar nas lavouras. Mas o que está óbvio nesta situação é que elas não estão em atividade de jogo, mas sim de trabalho. Assim, se instruirmos as crianças, mesmo as de pouca idade, elas provavelmente poderão operar de forma adequada com muitos objetos "do mundo adulto". Se isso ocorre, por que as crianças substituem os objetos? A função da substituição dos objetos utilizados pelo adulto reside no fato de que, deste modo, a criança pode estar livre para agir com a atividade do adulto como um todo. No exemplo analisado anteriormente, na brincadeira de médico, ao não ter que se ater ao produto da ação (curar a pessoas aplicando a injeção corretamente), a criança está livre para focar a sua atividade na apropriação da atividade adulta, o que significa lidar com os aspectos relativos às ações, operações e motivo, que é o central nessa fase para o seu processo de desenvolvimento e humanização.

É possível que uma criança de sete anos aprenda a operar realmente com uma injeção (auxiliando na aplicação em sua mãe que está doente, por exemplo), mas, ao fazêlo e ter a responsabilidade de fazê-lo para curar alguém, o objeto de sua consciência, aquilo para o qual a sua atividade está voltada, não é a atividade do médico, mas sim o ato de aplicar injeção. 
Ao operar com um pauzinho, fingindo ser a injeção, a criança pode trazer para a sua consciência, pode reproduzir em sua atividade de jogo, toda a estrutura da atividade adulta de ser médico: a relação do médico com o paciente (se é atencioso, soberbo etc), as operações de diagnóstico (investigando os sintomas, fazendo perguntas, anotando os dados em um papel, pedindo exames) e as ações de cura (aplicar injeção, receitar remédios etc). Em atividade de jogo, isto é, ao reconstituir a realidade por meio do jogo, a criança pode apropriar-se da estrutura da atividade humana, como suas ações e operações - parte executora - e seus objetivos, necessidades e motivos - parte orientadora. Ela descobre não só a relação dos homens com os objetos, mas também a relação das pessoas naquela determinada atividade (Davydov, 1987).

\section{Próximo}

\subsection{O jogo e a Zona de Desenvolvimento}

De acordo com as ideias de Leontiev (1988), atividade principal não é sinônimo de "atividade predominante", isto é, não é uma atividade na qual o indivíduo passa a maior parte de seu tempo. Uma atividade torna-se principal para a vida de um sujeito não pelo tempo que ele passa realizando essa atividade, mas sim pelo fato de que é através dela que são produzidas novas formas de conduta. Por conduta, entendemos um modo de o sujeito estar no mundo e agir nele; um modo de se relacionar com os outros e consigo mesmo. Desta forma, é através da atividade principal que ocorre o desenvolvimento histórico dos sujeitos, a formação das funções psíquicas superiores (Vygotski, 1995).

Retomando as discussões anteriormente realizadas a respeito da historicidade do jogo dentro do processo de filogênese e ontogênese, poderíamos nos perguntar o porquê e o como do Jogo tornar-se a atividade principal da criança em idade pré-escolar. O jogo, como já vimos, torna possível à criança concretizar as suas necessidades de agir com os objetos humanos e realizar ações humanas com eles, a despeito das mesmas não estarem diretamente acessíveis a ela. Essas ações são realizadas por um objeto que substitui o objeto original (do mundo adulto) e, embora não permitam à criança reproduzir o produto da atividade humana, permitem a ela reproduzir a estrutura da atividade, em suas dimensões de orientação e execução. Ao brincar de professor, reproduzindo as ações de ensino, a relação com os alunos e com os demais professores, fazendo cópias na lousa etc, não está em questão para a criança a concretização do objetivo da atividade de ensino (ensinar), mas a reprodução, por ela, daquilo que entende ser a atividade de ensino: o motivo, as ações e as operações.

Essa consideração leva-nos a uma afirmação quase consensual, dentro das teorias do jogo, a respeito de sua orientação para o processo e não para o produto. O motivo do jogo, como nos diz Leontiev (1988), está no processo. Entretanto, esta ideia precisa ser bem explicada. A criança não brinca de qualquer jeito, ela almeja reproduzir um determinado tema da realidade e da forma mais "fiel" possível. Aquestão não é que o jogo, em si mesmo, seja "puro processo", puro "prazer em fazer", mas que o objetivo está deslocado em relação à atividade adulta. Em outras palavras, a criança busca concretizar determinados objetivos no jogo, busca reproduzir da melhor maneira possível a atividade do mundo adulto que ela quer tornar acessível. Neste sentido, o jogo tem um objetivo, que podemos dizer ser consciente para a criança. A questão é que os resultados que a criança busca atingir (a reprodução da atividade) são, na atividade dos adultos, o processo. No exemplo dado anteriormente, a criança não objetiva ensinar outras crianças que estão brincando de professor/escolinha com ela, mas, justamente, reproduzir a atividade do professor.

Dessa forma, a criança age de modo consciente procurando desempenhar os papéis dos adultos em determinada atividade e, assim, descobre não só a relação dos homens com o objeto, mas, também, das pessoas entre si em uma determinada atividade (Leontiev, 1988). E, nesse processo, surgem novas formas de conduta. É nesse sentido que podemos compreender a relação entre a atividade do jogo e o desenvolvimento:

(...) o brinquedo fornece ampla estrutura básica para mudanças das necessidades e da consciência. A ação na esfera imaginativa, numa situação imaginária, a criação das intenções voluntárias e a formação dos planos da vida real e motivações volitivas - tudo aparece no brinquedo, que se constitui, assim, no mais alto nível de desenvolvimento préescolar (Vigotski, 2000, p. 135)

As formas culturais de conduta que são desenvolvidas no jogo referem-se, de uma maneira geral, ao comportamento voluntário: a atenção voluntária, a memória lógica e a própria voluntariedade. Esses tipos de conduta nascem em forma de colaboração, através de um "estímulo meio auxiliar" (Vygotski, 1995) que permite à criança controlar o seu comportamento.

O "estímulo meio auxiliar" no jogo protagonizado é desempenhado pelo papel representado pela criança na brincadeira. O papel que ela representa (médico ou professor, por exemplo) torna-se, durante o jogo, a referência do seu comportamento, torna-se o modelo, para a criança, das ações e relações (significados sociais) que ela deverá desempenhar. Esta, através do papel, pode começar a dominar os estímulos que incidem diretamente sobre ela e, assim, dominar o seu próprio comportamento, isto é, desenvolver uma conduta voluntária e não mais impulsiva?.

7 Se uma criança está brincando de "zoológico" com seus amigos e assume o papel de tratador dos animais, ela, muito provavelmente, se obrigará a cumprir as funções reais que o tratador de animais possui. Se seus amigos (que desempenham o papel de macacos) estão pulando pela grama e pelos galhos, e esta brincadeira the parecer divertida e lhe provocar o desejo de brincar também nos galhos, ela se submeterá à função de seu papel (que não the permite brincar nos galhos), e esperará a chance de ser macaco na brincadeira. É deste modo que o papel assumido pela criança desempenha a função de um instrumento psíquico externo, auxiliando a sua conduta voluntária, permitindo que sua conduta deixe de ser meramente reativa. 
Contudo, no jogo, essas novas formas de conduta apenas começam o seu processo de desenvolvimento e encontram-se no que Vygotski (1996) conceituou como zona de desenvolvimento próximo. As formas de conduta, ou as funções psíquicas da criança que se encontram na zona de desenvolvimento próximo, isto é, que ainda não são de domínio autônomo pela criança, que não foram internalizadas, não podem ser utilizadas de forma consciente e deliberada. Essas formas de comportamento, entretanto, podem ser utilizadas pelas crianças desde que em colaboração com indivíduos mais experientes de sua sociedade. Aliás, é justamente mediante essa colaboração que a criança pode se desenvolver, que as formas de comportamento ainda não dominadas por ela podem ser internalizadas, daí o motivo pelo qual Vigotski (2000, p. 134) afirma que o brinquedo

(...) cria uma zona de desenvolvimento proximal da criança. No brinquedo, a criança sempre se comporta além do comportamento habitual de sua idade, além de seu comportamento diário; no brinquedo, é como se ela fosse maior do que é na realidade.

O jogo de papéis, na condição de zona de desenvolvimento próximo, representa, portanto, a possibilidade máxima de aprendizagem em determinada etapa da vida da criança; representa o limite superior de seu desenvolvimento e, assim, a referência necessária para o processo educativo. É importante dizer que a aprendizagem que se dá na zona de desenvolvimento próximo, ao exigir uma forma de colaboração entre a criança e um indivíduo mais experiente, exige, também, que ocorra o processo de imitação/ reprodução por parte da criança. A imitação é um processo, necessariamente racional, baseado na compreensão da operação intelectual que se imita (Vygotski, 1996). Não cabe, portanto, dentro do conceito de zona de desenvolvimento próximo, o conceito de imitação mecânica. A imitação refere-se às operações intimamente relacionadas com a atividade racional da criança e ocorre em colaboração com um adulto, ou indivíduo mais experiente que ela. Com base nesse processo é que a função poderá ser internalizada, passando a fazer parte do nível de desenvolvimento real da criança.

O conceito de zona de desenvolvimento próximo apresenta uma estreita relação com os processos de aprendizagem e educação e, por isso, precisa ser muito bem compreendido antes de se transformar numa referência para o trabalho pedagógico.

Nem todas as atividades orientadas e direcionadas pelo adulto são atividades de colaboração no sentido elaborado por Vygotski (1996). A ajuda mecânica, específica ou pontual de uma tarefa que a criança desempenha, ou seja, a ajuda que se dirige à formação de hábitos ou técnicas, não se enquadra necessariamente no conceito de colaboração e, portanto, não se aplica à zona de desenvolvimento próximo. Queremos dizer com isso que esse tipo de auxilio não está direcionado a organizar e criar as condições para o processo de desenvolvimento da criança, ou seja, à formação de novas funções ou novas formas de condutas.
A confusão ou indistinção entre essas duas formas de intervenção ou auxílio pode resultar num abandono, na prática pedagógica, da organização de situações que concorram para o desenvolvimento das funções psíquicas superiores e das formas culturais de conduta. Se o adulto contribui ou auxilia um educando a executar um movimento simplesmente como um apoio físico (como na cambalhota) ou a resolver um problema de matemática simplesmente corrigindo suas contas, a colaboração resume-se a uma colaboração mecânica. Mas se esse auxílio se dá como uma forma de contribuição para o desenvolvimento cultural da criança, temos uma forma de trabalhar pedagogicamente na zona de desenvolvimento próximo (nos exemplos dados: fazer a criança perceber/conscientizar-se das partes do corpo envolvidas na cambalhota e como essas partes se relacionam entre si durante o movimento; ou fazendo a criança apropriar-se do conceito de número). Deste modo, o que o professor realiza, na prática, é uma efetiva relação consciente de seu trabalho como educador com a organização do desenvolvimento da criança ou do desenvolvimento do coletivo infantil.

\section{A intencionalidade pedagógica do jogo no trabalho educativo}

Defender o jogo como elemento essencial no processo de formação e educação da criança e, assim, nos processos de ensino-aprendizagem que se dão na escola, permite uma aproximação às propostas pedagógicas que veem no lúdico o elemento central da educação, especialmente na educação infantil. Todavia, para isto, é necessário discutir a intencionalidade pedagógica do jogo no trabalho educativo.

O lúdico, em muitas propostas pedagógicas, apresenta-se como sinônimo de prazer, como uma forma de exercício da máxima liberdade pela criança, como um momento de "livre expressão", desvinculado das "coerções" da sociedade. Essa compreensão possui uma raiz pedagógica nas teorias educacionais espontaneístas e nas concepções de infância como "natureza infantil", na qual a criança é vista como um ser que precisa ser socializado, "por meio de fatores não sociais - domínio corporal e emocional, diminuição do egocentrismo, acesso ao pensamento formal - aos quais acrescenta a convivência com outros indivíduos, adultos ou crianças" (Charlot, 1979, p. 259) e, então, a atividade lúdica apresenta-se como elemento central no processo educativo.

Essa visão representa, de um modo geral, a ideia de que, quanto menor a intervenção pedagógica no processo de formação da criança, mais livre ela será enquanto indivíduo. Entretanto, semelhante crença numa sociedade cuja esfera cotidiana da vida é marcada pela espontaneidade (Heller, 1989) apresenta, na verdade, possibilidades cada vez mais restritas para o desenvolvimento de cada ser humano. Ou seja, isto significa, concretamente, um abandono do indivíduo à sua própria sorte, daí a razão pela qual essa díade jogoprazer precisa ser superada, como indicou Vigotski (2000, p.121): 
(...) o prazer não pode ser visto como uma característica definidora do brinquedo, parece-me que as teorias que ignoram o fato de que o brinquedo preenche necessidades da criança nada mais são do que uma intelectualização pedante da atividade de brincar

Não se trata de criticar a ludicidade ou o prazer em si mesmos, de negar a importância do lúdico e do prazer no processo educativo (e na própria vida dos indivíduos), trata-se, isso sim, de compreender o lúdico e o prazer sobre outras bases. O lúdico é compreendido por nós como uma forma específica do homem se relacionar com o mundo, forma específica de efetivar as suas relações fundamentais de objetivação e apropriação e, assim, poder desenvolverse culturalmente. Considerando a atividade de trabalho como a atividade primária do homem, do ponto de vista de seu desenvolvimento filogenético (Marx \& Engels, 1977; Vygotski, 1995), as atividades lúdicas surgiram em etapas posteriores de sua vida, como uma forma não utilitária de atividade, assim como as artes. $\mathrm{Na}$ contemporaneidade, as atividades lúdicas mantêm a sua importância como atividades que permitem a explicitação das relações de apropriação e objetivação, sendo, apesar disso, atividades secundárias para os adultos ${ }^{8}$, mas essenciais para as crianças.

As atividades lúdicas, dentre elas o jogo de papéis, são fundamentais na vida da criança por significar, dentro de suas especificidades (físicas e as relacionadas à posição social), as suas máximas possibilidades de apropriação do mundo adulto, isto é, do mundo de relações, objetos, conhecimentos e ações historicamente criados pela humanidade. O jogo é a forma principal de a criança vivenciar o seu processo de humanização, uma vez que é a atividade que melhor permite à criança apropriar-se das atividades (motivos, ações e operações) culturalmente elaboradas. 0 jogo, para a criança em idade pré-escolar, é a atividade que melhor lhe permite ir se compreendendo como um ser em si e um ser para si.

O jogo é um recurso largamente empregado na educação infantil, etapa escolar em que o lúdico ou a brincadeira é um meio bastante utilizado nos processos de educação e aprendizagem. Neste sentido, o jogo é uma forma didática de trabalhar com os conteúdos e conhecimentos específicos das diferentes "áreas do saber". Seu uso nos processos educativos, portanto, não significa necessariamente trabalhar com a atividade principal da criança, ao menos não pedagogicamente, ou seja, organizada e direcionada intencionalmente. Se aplicarmos os conceitos de Leontiev (1983), podemos dizer que esse tipo de jogo faz parte da ação da criança e não de sua atividade. A finalidade e a organização do jogo como ação é a aprendizagem de hábitos ou conteúdos específicos, ao passo que o jogo como atividade da criança tem como finalidade a apropriação e o desenvolvimento de certas formas de culturais de comportamentos.

8 De acordo com a análise de Elkonin (1998), as atividades lúdicas no mundo adulto são representadas por formas mais evoluídas do jogo, notadamente o Esporte e as Artes.
Portanto, para termos um trabalho pedagógico fundamentado no jogo como atividade, não basta apenas utilizarmos o "recurso" jogo, ou seja, não basta aplicarmos jogos no processo educativo. Embora a utilização dos chamados "jogos didáticos" possa fazer parte do trabalho pedagógico da educação infantil, não é apenas por meio de seu uso que garantimos a organização da atividade principal da criança em idade pré-escolar. O trabalho com o "jogo didático" e com o jogo como atividade exige ações pedagógicas diferentes.

Podemos sintetizar nossas discussões a respeito da intencionalidade pedagógica do jogo no trabalho educativo destacando duas questões. A primeira delas relaciona-se aos limites do jogo para o desenvolvimento infantil. É certo que o jogo faz nascer determinadas formas culturais de conduta, mas isto não quer dizer que o desenvolvimento destas esteja completo. Isso quer dizer que a atividade do jogo, isoladamente, não tem a possibilidade de transformar os estímulos meios auxiliares (função da "representação" de um papel) em estímulos meios internos, isto é, em instrumentos psíquicos internalizados. Isso significa que as formas culturais de conduta, que começam a ser controladas pela criança no jogo, devem ser trabalhadas em outras atividades infantis (que não apenas o jogo), para se desenvolverem plenamente e se constituírem em funções psíquicas com as quais a criança possa operar deliberada e conscientemente.

Vygotski (conforme citado por Elkonin, 1998), quando discute as relações entre as funções psicológicas superiores e o jogo, é bastante preciso ao considerar que o caminho que vai do jogo aos processos internos, na idade escolar, é a fala interna, a integração, a memória lógica, o pensamento abstrato (sem coisas, mas com conceitos). É necessário entender esta conexão para compreender o principal na transição da idade pré-escolar para a escolar.

A outra questão, a respeito da intencionalidade pedagógica do jogo no trabalho educativo, remete para as possibilidades de uso do jogo protagonizado na educação. Embora a criança, em suas atividades cotidianas, elabore jogos protagonizados, não está negada ao professor a possibilidade de promover jogos, isto é, trabalhar pedagogicamente com a atividade principal da criança em idade pré-escolar. Todavia, o alerta de Elkonin (1998) sobre essa questão é de fundamental importância para dimensionarmos corretamente sua utilização. De acordo com ele, a importância pedagógica do jogo fica limitada em algumas situações porque a característica específica do jogo protagonizado - as relações sociais - assume uma função secundária em detrimento de um determinado conteúdo:

9 Nesse trabalho não iremos aprofundar a questão sobre os jogos didáticos, mas apontamos para a perspectiva de Leontiev na qual os jogos didáticos configuram-se como sendo "jogos de transição, quer para a atividade não lúdica, para a qual eles preparam diretamente o caminho, quer para os jogos do período escolar do desenvolvimento psíquico da criança. (Leontiev, 1998, p.140) 
Assim, por exemplo, pode-se organizar o jogo do armazém para ensinar as crianças a utilizarem medidas de peso. Para isso introduzem-se no jogo uma balança e pesos reais, entregam-se às crianças alguns grãos ou sementes secas, e elas aprendem a medir e pesar objetos variados, desempenhando as funções ora de vendedores, ora de compradores. Claro que nesses jogos as crianças podem aprender a pesar, medir, contar artigos por unidades e até fazer contas e dar o troco. As observações demonstram que no centro da atividade das crianças estão as operações com o peso e outras medidas, os cálculos etc. Mas se relegam a segundo plano as relações entre as pessoas no processo de "compra e venda" (Elkonin, 1998, p. 401).

Ao discutir, então, as possibilidades de uso do jogo protagonizado, a questão principal que se apresenta refere-se à sua intencionalidade. Nesse sentido, não se nega o emprego do jogo no trabalho pedagógico e a sua possibilidade de criar novas necessidades nas crianças e, assim, direcionar o seu desenvolvimento. Pelo contrário, considerar o jogo como a atividade principal da criança em idade pré-escolar e elaborar uma forma pedagógica de trabalhar com ele é uma tarefa da educação infantil. Porém, a ação educativa do educador, neste tipo de jogo, dá-se não apenas por sua ação direta nele, mas, também, na ação de organizar os materiais e conhecimentos sobre determinado Tema ${ }^{10}$ para serem apropriados pelas crianças. A criança, dessa forma, terá acesso à significação dos objetos culturais pela mediação do educador.

O que isso significa? Trata-se de dispor materiais que enriqueçam e direcionem a compreensão dos papéis a serem representados, ou seja, que enriqueçam e direcionem o tipo de apropriação dos elementos da vida ao redor das crianças, das relações interpessoais em determinada atividade do mundo adulto e suas ações. Assim, a intervenção do adulto no jogo da criança não só é possível como, também, desejável dentro do trabalho pedagógico.

Em termos práticos, essa intervenção, que visa auxiliar a criança na evolução do conteúdo de seus jogos e que procura contribuir para o desenvolvimento dos papéis que as crianças representam (tanto em termos das ações, quanto das interrelações dos personagens), pode manifestar-se de diversas maneiras. Destacamos algumas possibilidades de intervenção docente, como: brincar junto com as crianças; ler histórias a respeito de uma temática com a qual a criança esteja brincando em seus jogos; organizar uma visita a uma das situações presentes no brincar da criança etc. Todas essas formas de intervenção procuram explicitar, ainda mais, para a criança, a realidade com a qual ela está brincando em seus jogos, de modo que os conteúdos de suas brincadeiras possam, também, ser mais explícitos para elas e, nesse sentido, contribuam para o seu desenvolvimento. Em síntese, o trabalho do educador estaria, então, em "trazer" para a consciência das crianças a atividade a ser reconstituída por elas em forma de Jogo.

10 O Tema é a realidade que será reconstituída pelas crianças em forma de jogo (exemplo: brincar de Circo); o Conteúdo representa as ações e relações desempenhadas pelas pessoas nessa atividade (as ações e relações dos artistas com o público, as ações específicas do apresentador, do palhaço etc...) ( Elkonin, 1998).
Para que isto se torne possível, é preciso que o professor compreenda o percurso de desenvolvimento do jogo de papéis "que vai da ação concreta com os objetos à ação lúdica sintetizada e, desta, à ação lúdica protagonizada" (Elkonin, 1998, p.258). O exemplo dado por Elkonin é bastante claro: "(...) há colher, dar de comer com a colher; dar de comer com a colher à boneca; dar de comer à boneca como a mamãe" (Elkonin, 1998, p.259). Ou seja, não se trata de propor situações lúdicas nas quais as crianças interajam apenas com objetos, ou então, que reproduzam a relação que os adultos têm com esse objeto, mas, sobretudo, de propor situações nas quais estejam latentes as relações das pessoas entre si.

Isto significa considerar que, na educação infantil, o trabalho educativo com o jogo tem por objetivo revelar as relações humanas presentes nele, para que as crianças possam delas se apropriar. O caminho investigativo a ser trilhado, no caso da educação infantil, passa tanto pela necessidade de pesquisas, na escola, referentes à função social do jogo no trabalho pedagógico, quanto pela necessidade de pesquisas em situações de ensino (experimentalmente organizadas), de modo a analisarmos em que medida os estudos sobre o jogo realizados por Vigotski, Leontiev, Luria e, particularmente, Elkonin, configuram-se, em fundamentos teórico-metodológicos decisivos para o estabelecimento de uma nova proposta de ensino e aprendizagem na e para a educação infantil.

\section{Referências}

Brougère, G. (1998). Jogo e educação. Porto alegre: Artes Médicas.

Charlot, B. (1979). A mistificação pedagógica. Realidades sociais e processos ideológicos na teoria da Educação. Rio de Janeiro: Zahar Editores.

Davidov, V. V. (1987). La ensenanza escolar y el desarrollo psíquico. Moscou: Editorial Progresso.

Elkonin, D. B. (1969). Característica general del desarrolo psíquico de los ninos. Em A. A. Smirnov et. al., Psicología (pp. 493-503). México: Grijalbo.

Elkonin, D. B. (1998). Psicologia do jogo. São Paulo: Martins Fontes.

Heller, A. (1989). Cotidiano e história. Rio de Janeiro: Paz e Terra.

Leontiev, A. N. (1983). Actividad, consciencia, personalidad. Havana: Editorial Pueblo y Educación.

Leontiev, A. N. (1987). O desenvolvimento do psiquismo. Lisboa: Nova horizonte.

Leontiev, A. N. (1988). Os princípios psicológicos da brincadeira pré-escolar. Em Vigotski et al., Linguagem, desenvolvimento e aprendizagem (pp.119-142). São Paulo: Ícone.

Marx, K., \& Engels, F. (1977). A ideologia alemã. São Paulo: Grijalbo.

Ruiz, R. O. (1992). El juego infantil y la construccion social del conocimiento. Sevilla, Espanha: Ediciones Alfar.

Saviani, D. (2003). Pedagogia histórico-crítica. Campinas: Autores Associados. 
Shuare, M. (1990). La psicologia pedagógica tal como y ola veo. Moscou: Progresso.

Vigotski, L. S. (2000). A formação social da mente. São Paulo: Martins Fontes.
Vygotski, L. S. (1995). Obras escogidas (Vol. III). Madri: Visor.

Vygotski, L. S. (1996). Obras escogidas (Vol. IV). Madri: Visor.

Recebido em: $26 / 12 / 2008$

Reformulado em: 14/07/2009

Aprovado em: 18/07/2009

\section{Sobre as Autoras}

Carolina Picchetti Nascimento (carolina_picchetti@hotmail.com)

Universidade de São Paulo.

Elaine Sampaio Araujo (esaraujo@usp.br)

Faculdade de Filosofia, Ciências e Letras de Ribeirão Preto da Universidade de São Paulo.

Marlene da Rocha Migueis (mmigueis@dce.ua.pt)

Faculdade de Aveiro de Portugal.

\section{Correspondência}

Elaine Sampaio Araújo

FFCLRP/Departamento de Psicologia e Educação

Av: Bandeirantes, 3900

CEP: $1404-901$

Ribeirão Preto/ São Paulo - Brasil

\section{Agradecimentos}

A todos os membros do Grupo de Estudos e Pesquisa sobre Atividade Pedagógica - (GEPAPE) - pelas contribuições da discussão sobre o tema. 